\title{
Teaching Note
}

\author{
Getting into an Argument
}

\author{
ARNOLD WILSON University of Cincinnati
}

Most introductory logic courses spend time acquainting students with the concepts of premise, conclusion, deduction, induction, logical indicators, and so on. For a long time I thought this all fairly obvious material until one term I discovered what I thought to be a perverse group of students. Despite the care I had taken in discussing this material they did very poorly on a quiz later. They could not identify premises or conclusions in simple arguments. Many could not figure out how "because" works, and some even failed to identify it as a logical operator.

Before the next class I struck on a plan to teach all this with much less chalk and handwaving. I would get them all into arguments! On a series of $3 \times 5$ cards I wrote out a variety of arguments, one statement per card. On others I wrote premise and conclusion indicators. Thus:

$\begin{array}{ll}\begin{array}{l}\text { Statement cards } \\ \text { Either Ted or Jake }\end{array} & \text { Indicator cards } \\ \text { came from Utah } & \\ \text { Ted is not from } & \text { Therefore } \\ \text { Utah } & \\ \text { Jake is from Utah } & \text { (as needed) } \\ \text { (and similar) } & \end{array}$

The idea was to have one card for each student; a card that would fit with others to produce an argument. I passed the cards out as they came into class, and later challenged them "to get into an argument." They wandered around comparing cards to see who "fit" their argument. The content of the statement cards was the guide, but I didn't tell them this. I gave no special instructions about the logical operators; I hoped they would just fit in. At first they felt lost, but soon others were yelling "We need a Since". Because I expected stragglers, but couldn't guess how many, I made a couple of elastic inductive arguments, allowing newcomers to fit into an already complete argument (nothing worse than a conclusion who cannot find premises to support it.) So at least one argument series was like this:

Sue likes pizza and Everybody likes and 7-up pizza and 7-up

Sal likes pizza and

7-up

Cal likes pizza and

$$
\text { 7-up }
$$

(etc...)

As the "arguments" began forming, I announced that each group was to go to one of the chalk boards; each student to write out their part of the argument, and to list their names at the side.

It worked great. They thought this part Kooky but fun, and it took about five minutes. Then I asked the telling questions, sometimes to those in the 
argument under scrutiny, sometimes to others to keep class attention. (Now acquainted, they wanted to chat!) "How did you know that someone fit into your argument?" "Why is this the conclusion instead of that?" "Why did you put the conclusion first?" "Is this a good argument?"

The exercise served well to distinguish deductive and inductive forms. (I showed them the extra cards and asked if the argument would have been "stronger" if one more person came to class.) We saw that they could recognize an argument even if invalid. The "principle of charity" was identified and understood. They saw how arbitrary but helpful are various "indicators."
We learned more in forty minutes than ever before-plus they learned everyone's name.

I have since used the idea many times and have made some improvements. (Now I use $5 \times 8$ cards.) It is a good icebreaker for a group of 20 to 40 students, and reinforces the notion that they really do have an intuitive grasp of many of the basic ideas of logic. And its usefulness was evident all term as I recalled it to the class to illustrate some new but relevant point.

Arnold Wilson, University College, University of Cincinnati, Cincinnati, Ohio 45221-0206 USA 